\title{
Implementing a comprehensive cervical cancer program in Southern Malawi: a 'Médecins Sans Frontières', Ministry of Health, and College of Medicine of Blantyre Collaborative Project
}

\author{
George Chilinda, Blantyre, Malawi; Leo Massamba, Blantyre, Malawi; Samuel Meja (D) , Blantyre, Malawi; \\ Charlotte Ngo, Paris, France and Pierre-Francois Dupre, Brest, France
}

Driven by the high prevalence of human papillomavirus and HIV $(10.8 \%),{ }^{1}$ early sexual debut, and high parity, Malawi ranks as the country with the second highest cervical cancer incidence (agestandardized rate of 72.9/100 000) and mortality (age-standardized rate of $54.5 / 100000$ ) worldwide. ${ }^{2}$ In response to this, the Malawian Ministry of Health started a Cervical Cancer Control program in 1999, which was scaled up to all Malawian districts by 2011. As a long-standing health partner in the HIV program in Malawi, 'Médecins Sans Frontières' decided to strengthen the Ministry of Health strategy by implementing a comprehensive onco-gynecological program in Southern Malawi in collaboration with the Ministry of Health and the College of Medicine.

The program encompasses all stages of cervical cancer disease course including immunization, screening, treatment, and palliative care. ${ }^{3}$ Médecins Sans Frontières is strengthening the onco-gynecological treatment capacity in a multimodal way in order to ensure a strong operational capacity and a target of sustainability. This logistic approach encompasses the building of dedicated onco-gynecological outpatient (Figure 1) and inpatient departments and an operating theater (Figure 2) within the tertiary care Queen Elizabeth Central Hospital (QECH) in Blantyre, as well as a referral pathway for eligible patients to undergo chemoradiation in neighboring countries since no radiotherapy is currently available in Malawi. A tailored approach has been developed in close collaboration with the Obstetrics/ Gynecology and Oncological Department

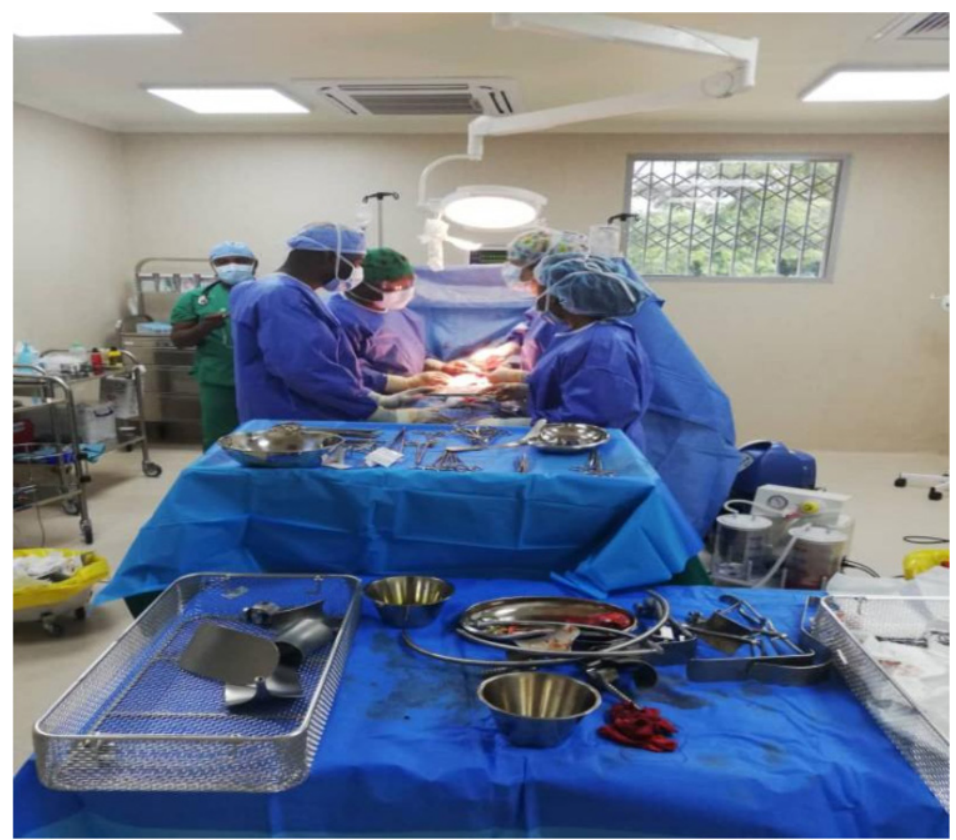

Figure 1 National Malawian and Médecins Sans Frontières expatriate staff working together in the new operating theater.

of $\mathrm{QECH}$ in accordance with their own experience in neoadjuvant chemotherapy treatment while Médecins Sans Frontières is organizing a new form of 'on site' fellowship through short rotations of gynecological oncologists to support national staff.

Our guidelines encompass International Federation of Gynaecology and Obstetrics (FIGO) 2018 ultrasound staging and upfront or post-neoadjuvant chemotherapy radical hysterectomy according to the Querleu-Morrow classification and European Society of Gynaecological Oncology (ESGO) stratification risk. Special attention is given to therapeutic patient education, social assessment, and support as poverty significantly decreases the likelihood that patients will adhere to treatment and follow-up. ${ }^{4}$ Resources should be balanced across prevention and treatment in order to maximize the influence on cancer incidence and mortality in support of the Ministry of Health capacities. Quality control is based on the implementation of a longitudinal database and an electronic medical record (Bahmni) ${ }^{5}$ in order to link screening, diagnosis, and treatment with survival data. Continuous assessment of this project will give us valuable real-world experience in treating solid tumors in a resource-limited context with the objective of building a ubiquitous cancer care strategy in low- and middleincome countries. 


\section{Corners of the world}

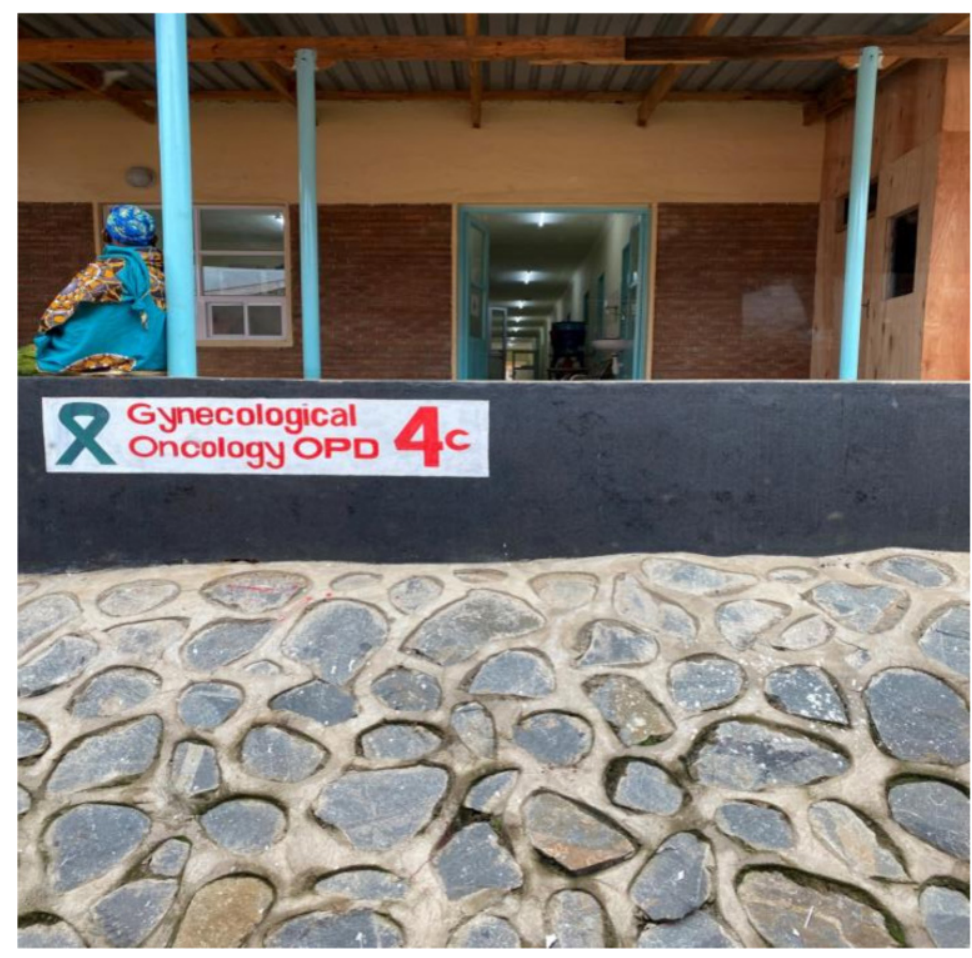

Figure 2 Gynecological oncology outpatient department.

The sustainability of such a project faces three major challenges: resources, continuous assessment of quality, and medical education.

Correspondence to Dr Pierre-Francois Dupre, Breast \& Gynaecological Oncology, CHU Brest, Brest, France; pierre-francois.dupre@chu-brest.fr

Acknowledgements Médecins Sans Frontières donors, Prof. Denis Querleu.
Collaborators Denis Querleu, Jerome Blanchot.

Contributors CN, P-FD, LM, and GC supervised the project. P-FD wrote the manuscript with the support of GC and LM. SM and GC developed the clinical aspects. All the authors discussed and contributed to the final manuscript.

Funding The authors have not declared a specific grant for this research from any funding agency in the public, commercial or not-for-profit sectors.

Competing interests None declared.
Patient consent for publication Not required.

Provenance and peer review Not commissioned; externally peer reviewed.

(C) IGCS and ESG0 2021. No commercial re-use. See rights and permissions. Published by BMJ.

D) Check for updates

To cite Chilinda G, Massamba L, Meja S, et al. Int J Gynecol Cancer Published Online First: [please include Day Month Year]. doi:10.1136/ijgc-2021-002743

Accepted 7 May 2021

Int J Gynecol Cancer 2021;0:1-2.

doi:10.1136/ijgc-2021-002743

\section{ORCID iD}

Samuel Meja http://orcid.org/0000-0001-9252-1986

\section{REFERENCES}

1 Malawi Government Ministry of Health. Demographic and Health Survey Malawi, 2015

2 Bray F, Ferlay J, Soerjomataram I, et al. Global Cancer Statistics 2018: GLOBOCAN estimates of incidence and mortality worldwide for 36 cancers in 185 countries. CA Cancer J Clin 2018;68:394-424.

3 Arrossi S, Matos $\mathrm{E}$, Zengarini $\mathrm{N}$, et al. The socio-economic impact of cervical cancer on patients and their families in Argentina, and its influence on radiotherapy compliance. results from a cross-sectional study.. Gynecol Oncol 2007;105:335-40.

4 BahmniTM Open Source EMR. Available: https://www.bahmni.org

5 Mezei AK, Armstrong HL, Pedersen HN, et al. Cost-effectiveness of cervical cancer screening methods in low- and middleincome countries: a systematic review. Int $J$ Cancer 2017;141:437-46. 